\title{
Striatal Neuroprotection from Neonatal Hypoxia-Ischemia in Piglets by Antioxidant Treatment with EUK-134 or Edaravone
}

\author{
Xinli $\mathrm{Ni}^{\mathrm{a}}$ Zeng-Jin Yang ${ }^{\mathrm{a}}$ Erin L. Carter ${ }^{\mathrm{a}}$ Lee J. Martin ${ }^{\mathrm{b}, \mathrm{c}}$ Raymond C. Koehler \\ ${ }^{a}$ Department of Anesthesiology and Critical Care Medicine, ${ }^{b}$ Division of Neuropathology, Department of \\ Pathology, and ' Department of Neuroscience, Johns Hopkins University, Baltimore, Md., USA
}

\section{Key Words}

Asphyxia - Cardiopulmonary resuscitation - Free radical scavenger $\cdot \mathrm{MCl}-186 \cdot 8$-Nitroguanosine $\cdot$ Nitrotyrosine $\cdot$ Oxidative stress $\cdot$ Superoxide dismutase

\begin{abstract}
Striatal neurons are highly vulnerable to hypoxia-ischemia $(\mathrm{HI})$ in term newborns. In a piglet model of HI, striatal neurons develop oxidative stress and organelle disruption by 3-6 h of recovery and ischemic cytopathology over 6-24 h of recovery. We tested the hypothesis that early treatment with the antioxidants EUK-134 (a manganese-salen derivative that acts as a scavenger of superoxide, hydrogen peroxide, nitric oxide or $\mathrm{NO}$ and peroxynitrite) or edaravone $(\mathrm{MCl}-$ 186 , a scavenger of hydroxyl radical and NO) protects striatal neurons from $\mathrm{HI}$. Anesthetized newborn piglets were subjected to $40 \mathrm{~min}$ of hypoxia and $7 \mathrm{~min}$ of airway occlusion. At 30 min after resuscitation, the piglets received vehicle, EUK134 or edaravone. Drug treatment did not affect arterial blood pressure, blood gases, blood glucose or rectal temperature. At 4 days of recovery, the density of viable neurons in the putamen of vehicle-treated piglets was $12 \pm 6 \%$ $( \pm S D)$ of sham-operated control density. Treatment with EUK-134 increased viability to $41 \pm 17 \%$, and treatment with edaravone increased viability to $39 \pm 19 \%$. In the caudate nucleus, neuronal viability was increased from $54 \pm 11 \%$ in
\end{abstract}

the vehicle group to $78 \pm 15 \%$ in the EUK-134 group and to $73 \pm 13 \%$ in the edaravone group. Antioxidant drug treatment accelerated recovery from neurologic deficits and decreased oxidative and nitrative damage to nucleic acids. Treatment with EUK-134 reduced the HI-induced formation of protein carbonyl groups and tyrosine nitration at $3 \mathrm{~h}$ of recovery. We conclude that systemic administration of antioxidant agents by 30 min after resuscitation from $\mathrm{HI}$ can reduce oxidative stress and salvage neurons in the highly vulnerable striatum in a large-animal model of neonatal $\mathrm{HI}$. Therefore, oxidative stress is an important mechanism for this injury, and antioxidant therapy is a rational, mechanismbased approach to neuroprotection in the newborn brain.

Copyright $\odot 2011$ S. Karger AG, Basel

\section{Introduction}

Oxidative stress is thought to play an important role in the biochemical cascade that leads to neuronal cell death after hypoxia-ischemia (HI) in the newborn $[1,2]$. Experimental evidence in postnatal-day-7 (P7) rodents

Present address of Xinli Ni: Department of Anesthesiology Affiliated Hospital of Ningxia Medical University

Yinchuan, 750004 (China)

\section{KARGER}

๑ 2011 S. Karger AG, Basel

Fax +4161306 1234

E-Mail karger@karger.ch

www.karger.com
Accessible online at: www.karger.com/dne
Raymond C. Koehler, PhD

Department of Anesthesiology and Critical Care Medicine

The Johns Hopkins Medical Institutions, 600 North Wolfe Street/Blalock 1404 Baltimore, MD 21287-4961 (USA)

Tel. +1 410955 4068, E-Mail rkoehler@jhmi.edu 
indicates high levels of oxidative and nitrative stress in the brain after HI that appear to be related to relatively high levels of free iron, low expression of antioxidant enzymes such as glutathione peroxidase, and generation of hydrogen peroxide and other reactive oxygen species (ROS) [3-5]. The mitochondria and perhaps xanthine oxidase are thought to be major sources of ROS [6], whereas $\mathrm{NADPH}$ (nicotinamide adenine dinucleotide phosphate) oxidase may be a less important source in the immature brain [7]. Antioxidant drugs such as allopurinol [8, 9], deferoxamine [10], tirilazad [11], $\mathrm{N}$-acetylcysteine [12] and edaravone [13-17] have been reported to reduce oxidative stress and improve outcome in postnatal rodents after HI. Thus, early treatment with antioxidant drugs is a potential therapy for neonatal HI encephalopathy in humans. In this regard, testing the efficacy of antioxidant drugs in a large-animal model of neonatal HI would be useful for preclinical evaluation.

The topology of brain injury in piglets subjected to combined hypoxia and asphyxia is similar to that seen in term newborns with HI encephalopathy [18-20]. In particular, striatal neurons are selectively vulnerable in both piglets and human newborns at term. Medium spiny neurons in piglet putamen undergo rapid and progressive neurodegeneration between 6 and 24 h of recovery [21, $22]$. Ultrastructural damage to organelles becomes prominent by $3-6 \mathrm{~h}$ [21]. The evidence for oxidative stress as a mechanism for brain damage is robust in this model. Glutathione depletion and markers of oxidative and nitrative damage to proteins and nucleic acids precede neuronal cell death and are evident at $3 \mathrm{~h}$ of recovery in piglet putamen [21-24]. Therefore, this model of HI injury should be useful for testing the efficacy of antioxidant drugs.

In the present study, we used a model of hypoxia plus asphyxia to test the efficacy of two structurally and mechanistically different antioxidant drugs, edaravone (3-methyl-1-phenyl-2-pyrazolin-5-one; MCI-186) and EUK-134 [manganese 3-methoxy $N, N^{\prime}$-bis(salicylidene) ethylenediamine chloride]. As a direct scavenger of hydroxyl radicals and nitric oxide (NO) [25], edaravone has been shown to be effective in clinical stroke and has been approved for use in adult stroke patients in Japan [26]. It also has been found to reduce lipid peroxidation and brain injury from $\mathrm{HI}$ in immature rats [13-16]. EUK-134 is a member of the manganese-salen subtype of catalytic antioxidants and is able to prevent the formation of hydroxyl radicals through the catalytic removal of the superoxide anion and hydrogen peroxide [27]. By virtue of its superoxide dismutase (SOD) and catalase-mimetic functions, EUK-134 has been shown to provide effective protection against oxidative damage [28-30]. EUK-134 can also oxidize NO and peroxynitrite and thereby reduce nitrosative stress [31]. Systemic administration of EUK-134 has been reported to protect the brain from kainate excitotoxicity and focal cerebral ischemia $[32,33]$. Because of its broad ability to alleviate both oxidative and nitrosative stress, EUK-134 may be a useful manganese-salen prototype for alleviating oxidative and nitrosative stress known to occur in perinatal HI. Here, we evaluated the ability of EUK134 and edaravone to ameliorate $\mathrm{HI}$ damage in piglet striatum and to reduce markers of oxidative and nitrosative stress on nucleic acids and proteins.

\section{Materials and Methods}

\section{Hypoxic-Ischemic Protocol}

All procedures received approval from the animal care and use committee of the Johns Hopkins University and were modified from the method described previously [23, 24]. Briefly, 3- to 7 -day-old piglets $(2-3 \mathrm{~kg})$ were anesthetized with sodium pentobarbital ( $50 \mathrm{mg} / \mathrm{kg}$, intraperitoneally). The trachea was intubated and the lungs were ventilated with a fraction of inspired oxygen $\left(\mathrm{FiO}_{2}\right)$ of 0.30 in humidified air. Ventilation was adjusted to keep end-tidal $\mathrm{CO}_{2}$ at $35-45 \mathrm{~mm} \mathrm{Hg}$. The animals were kept normothermic $\left(38.5-39.5^{\circ} \mathrm{C}\right.$, rectal) throughout the experimental procedure via heated blankets and overhead lamps. Using aseptic surgical techniques, sterile femoral catheters were inserted into the descending aorta and inferior vena cava through the right groin, tunneled subcutaneously, and secured to a right flank exit incision, where long-term access was obtainable. Surgical sites were closed with sterile sutures. Piglets received an intravenous maintenance infusion of $5 \%$ dextrose and $0.45 \%$ saline at $10 \mathrm{ml} / \mathrm{h}$. Fentanyl (20 $\mu \mathrm{g} / \mathrm{kg}$, intravenously) was given during surgery to maintain anesthesia, pancuronium bromide $(0.3 \mathrm{mg} / \mathrm{kg}$, intravenously) was administered to produce muscle paralysis during hypoxia and asphyxia, and the antibiotic cephalothin $(0.3 \mathrm{mg} / \mathrm{kg}$, intravenously) was administered to reduce infection risk.

After a postsurgical stabilization period of $20 \mathrm{~min}$, baseline measurements of arterial blood gases, hemoglobin content, $\mathrm{O}_{2}$ content, glucose concentration, arterial blood pressure, heart rate and rectal temperature were recorded. Hypoxia was induced by decreasing $\mathrm{FiO}_{2}$ to 0.10 for $40 \mathrm{~min}$. Subsequently, the piglets underwent ventilation with room air for $5 \mathrm{~min}$ to permit partial reoxygenation necessary for later cardiac resuscitation. The endotracheal tube was then clamped for $7 \mathrm{~min}$. Cardiopulmonary resuscitation was initiated by unclamping the endotracheal tube, reinstating ventilation with $50 \%$ oxygen at a rate of 28 breaths/ min, manually compressing the chest $(100 / \mathrm{min})$ and injecting epinephrine $(100 \mu \mathrm{g} / \mathrm{kg}$, intravenously) as a bolus until return of spontaneous circulation (ROSC). A second injection of epinephrine was administered if ROSC did not occur. Defibrillation was performed when needed. Piglets that did not achieve ROSC within $3 \mathrm{~min}$ of resuscitation were excluded. After resuscitation, $\mathrm{FiO}_{2}$ was gradually reduced to 0.30 to maintain arterial oxyhemoglobin saturation higher than $95 \%$, as guided by arterial blood analysis. Sodium bicarbonate was administered to correct base defi- 
cits of $>5 \mathrm{~mm}$. Arterial blood pressure, blood gases, $\mathrm{pH}$ and glucose were monitored until the piglets regained consciousness. The piglets were extubated when they began to regain consciousness, usually at 6-8 h after ROSC. Sham control animals were anesthetized and subjected to the surgical preparation but not HI. The piglets recovered in an individual cage with a warming blanket and received an intravenous infusion of $5 \%$ dextrose and $0.45 \%$ saline for the first $12-24 \mathrm{~h}$ of recovery. They were fed formula milk from a syringe during the first day of recovery. By the second day, they usually were able to drink milk from a bowl and were housed with a littermate.

\section{Drug Treatments}

At $30 \mathrm{~min}$ after ROSC (or equivalent time in sham piglets), EUK-134 (2.5 mg/kg plus $1.25 \mathrm{mg} / \mathrm{kg} / \mathrm{h}$ for $3.5 \mathrm{~h}$; Cayman Chemical, Ann Arbor, Mich., USA) or edaravone (MCI-186; 3 mg/kg plus $1.5 \mathrm{mg} / \mathrm{kg} / \mathrm{h}$ for $5.5 \mathrm{~h}$; Cayman Chemical) were administered intravenously. Control animals received the same infusion volume of vehicle $(0.9 \%$ saline vehicle for EUK-134 or 10\% 2-hydroxypropyl- $\beta$-cyclodextrin vehicle for edaravone). A short delay of 30 min after ROSC for drug administration was used because administration of drugs to newborns immediately after birth is technically difficult. The loading doses of $2.5 \mathrm{mg} / \mathrm{kg}$ for EUK-134 and $3 \mathrm{mg} / \mathrm{kg}$ for edaravone were based on studies showing that these doses were highly effective in reducing infarct volume from focal cerebral ischemia in adult animals $[32,34,35]$. Because cell death in the striatum becomes evident by $6 \mathrm{~h}$ after ROSC in this piglet model $[21,22]$, a maintenance infusion of the drugs was used for 4-6 h after ROSC. A maintenance infusion rate equivalent to one half of the loading dose per hour was chosen. In the case of edaravone, the cumulative intravenous dose of $11.5 \mathrm{mg} / \mathrm{kg}$ over $6 \mathrm{~h}$ was of a similar order of magnitude to 2 daily intraperitoneal injections of $9 \mathrm{mg} / \mathrm{kg}$ shown to be effective in $\mathrm{P} 7$ rats exposed to $\mathrm{HI}$ [15], and to 2 intraperitoneal injections of $10 \mathrm{mg} / \mathrm{kg}$ shown to be effective in P9 harlequin mice exposed to HI [17].

\section{Neurologic Deficit Assessment}

Neurobehavioral assessments were performed at 1, 2, 3 and 4 days after HI. Neurologic deficits were graded on a scale of $0-154$ (normal score: 0; maximal deficit score: 154), as described previously [36]. The composite score is the summation of grades of individual assessments of level of consciousness (0-15), brainstem function (0-22), sensory responses (0-20), motor function (0-46), spatial orientation $(0-20)$, behavioral activity $(0-16)$ and seizure activity $(0-15)$.

\section{Histologic and Immunohistochemical Evaluation}

At day 4 of recovery, the piglets were anesthetized deeply with sodium pentobarbital (100 $\mathrm{mg} / \mathrm{kg}$, intraperitoneally), and an intra-aortic catheter was placed through the left ventricle. Exsanguination was started immediately with $100 \mathrm{~mm}$ ice-cold $\left(4^{\circ} \mathrm{C}\right)$ phosphate-buffered saline (PBS, pH 7.4) and continued for at least $5 \mathrm{~min}$. When clear venous reflux from the punctured right atrium was observed, cold $\left(4^{\circ} \mathrm{C}\right) 4 \%$ paraformaldehyde was perfused for $20 \mathrm{~min}$. Brains were removed and bisected midsagittally, and each hemisphere was cut coronally into $1-\mathrm{cm}$ slabs. The left forebrain was paraffin embedded for histologic staining with hematoxylin and eosin (HE). The right forebrain was cryoprotected in $20 \%$ glycerol-PBS for $24 \mathrm{~h}$, frozen and cut into serial $50-\mu \mathrm{m}$ sections through the putamen.

Neuroprotection from Neonatal HI by

Antioxidant Treatment
To assess neuronal damage, HE-stained paraffin sections (10 $\mu \mathrm{m})$ were examined by light microscopic examination at $\times 1,000$ magnification with a field of $0.03 \mathrm{~mm}^{2}$. A profile counting-based assessment was performed. Injury was assessed in brain sections that were matched identically for level. In each region, the number of viable neurons was counted in 7 nonoverlapping, contiguous microscopic fields by an observer blinded to treatment. Neuronal viability was assumed when no evidence was found for eosinophilic cytoplasm, cytoplasmic vacuolation, cell body shrinkage or nuclear pyknosis. Regions counted included the putamen, caudate nucleus and layer $\mathrm{V}$ of the parasagittal gyrus at the midstriatal coronal level (primary sensorimotor cortex). Injury was found to be most dense at this coronal level. The 7 values for each section were averaged to obtain a single value of viable neurons per square millimeter for each piglet to be used in the statistical analysis.

Piglet striatal neurons undergo DNA and RNA oxidative and nitrative damage after $\mathrm{HI}[21,24]$. Immunohistochemistry was carried out on free-floating sections to detect 8-hydroxy-2'deoxyguanosine (8-OHdG) and 8-nitroguanosine in putamen. Endogenous peroxidase was quenched by 30 -min incubation in $0.6 \%$ $\mathrm{H}_{2} \mathrm{O}_{2}$. Sections were blocked in $10 \%$ normal horse serum $(0.4 \%$ Triton X-100) and incubated with mouse anti-8-OHdG (1:1,500; QED Bioscience Inc., San Diego, Calif., USA) or anti-8nitroguanosine (1:2,000; Dojindo, Japan) for $24 \mathrm{~h}$ at $4^{\circ} \mathrm{C}$. After being rinsed in $\mathrm{PBS}$, sections were incubated with biotinylated antimouse IgG (1:200; Vector Laboratories, Burlingame, Calif., USA) and VECTASTAIN Elite ABC reagent (Vector). Immuno-staining was developed with diaminobenzidine as a chromogen (Vector).

\section{Protein Oxidation and Nitration Assays}

Fresh brain tissue was subjected to subcellular fractionation, as described previously [23]. At $3 \mathrm{~h}$ of recovery from $\mathrm{HI}$ or an equivalent time in sham-operated piglets, $30 \mathrm{mg} / \mathrm{kg}$ pentobarbital was administered intravenously, and the animal was perfused transcardially with ice-cold PBS. Brains were removed rapidly, transected midsagittally and subdissected carefully to obtain samples selectively from putamen. Tissues were homogenized in ice-cold homogenization buffer $[20 \mathrm{mM}$ Tris- $\mathrm{HCl}$ ( $\mathrm{pH} 7.4)$ with $30 \%$ sucrose, $1 \mathrm{~mm}$ ethylenediaminetetraacetate, $0.2 \mathrm{mM}$ phenylmethylsulfonyl fluoride and protease inhibitor cocktail (Roche, Germany)] and centrifuged at $4{ }^{\circ} \mathrm{C}$ and $1,000 \mathrm{~g}$ for $10 \mathrm{~min}$. The supernatant was removed and centrifuged at $54,000 \mathrm{~g}$ for $40 \mathrm{~min}$. The resulting membrane-enriched pellet was resuspended and washed with sucrose-free homogenization buffer and centrifuged at $54,000 \mathrm{~g}$ for $40 \mathrm{~min}$ twice. The final pellet was resuspended in homogenization buffer that contained $20 \%$ glycerol instead of sucrose. Samples were stored at $-80^{\circ} \mathrm{C}$.

To determine if striatal neurons undergo oxidative stress, peroxynitrite-mediated damage to proteins was identified by using anti-3-nitrotyrosine antibody. Samples (20 $\mu \mathrm{g}$ of protein) were separated by $4-12 \%$ sodium dodecyl sulfate (SDS) polyacrylamide gel electrophoresis and electrotransferred onto nitrocellulose membranes. After being blocked with $5 \%$ nonfat milk in $0.01 \mathrm{M}$ TBST (Tris-buffered saline $+0.05 \%$ Tween 20 , pH 7.4) for $1 \mathrm{~h}$, the membranes were probed overnight at $4{ }^{\circ} \mathrm{C}$ with anti-nitrotyrosine (1:10,000; Upstate, Lake Placid, N.Y., USA) or anti-synaptophysin (1:20,000; Chemicon, Temecula, Calif., USA). Membranes were then washed and incubated with goat anti-mouse $\operatorname{IgG}(0.2 \mu \mathrm{g} / \mathrm{ml})$ as secondary antibodies conjugated to horseradish peroxidase (Amersham, Piscataway, N.J., USA). Blots were again washed, and 
immunoreactive bands were visualized by an enhanced chemiluminescence detection system (Amersham). Synaptophysin (p38), a synaptic vesicle membrane protein whose level does not change during the first $24 \mathrm{~h}$ after HI [21], was used as a protein loading standard.

For oxidative modification, protein carbonylation is often used as a marker of damage that results from superoxide and hydroxyl radicals. To detect oxidative modification of proteins in the piglet striatum after HI, we used an OxyBlot Protein Oxidation Detection Kit (Chemicon) for carbonyl groups [22]. Aliquots of equal amounts of protein $(20 \mu \mathrm{g})$ were denatured with $10 \%$ SDS, then derivatized to 2,4-dinitrophenylhydrazone (DNP) by a reaction with 2,4-dinitrophenylhydrazine (DNPH) for $5 \mathrm{~min}$. This reaction allows for a chemical conjugation of DNPH to the carbonyl group of the protein side chain to create a hydrazone moiety that can be immunodetected. The reaction was quenched with a neutralizing solution, and a characteristic color change to brown followed. Samples were then placed on ice and loaded onto 4-12\% SDS polyacrylamide gels for SDS-polyacrylamide gel electrophoresis. Proteins with conjugated DNP residues were detected with polyclonal rabbit antibody to DNP used at a concentration of 1:150. Proteins were then visualized with goat anti-rabbit IgG (horseradish peroxidase-conjugated) antibody (1:300) and by enhanced chemiluminescence, and were exposed to radiographic film.

Four independent immunoblot experiments were carried out for 3-nitrotyrosine and DNP immunoreactivity. Protein samples derived from the putamen of individual piglets from the shamsaline, sham-EUK-134, HI-saline and HI-EUK-134 treatment groups were loaded onto gels. Relative protein levels were expressed as the percentage of the sham-saline values by comparing the immunodensity of the protein bands (average integration of density and area of immunoreactivity) with the immunodensity of the same bands in the sham-saline control lane of the same blot.

Data and Statistical Analysis

The sample size calculation was based on the primary endpoint of viable neuronal counts in putamen. In a previous study [24], the $\mathrm{SD}$ of viable neurons in $\mathrm{HI}$ piglets was $11.4 \%$ of the control value. With this estimated SD, a difference of $20 \%$ of the control value should be detectable between two HI treatment groups with a sample size of 8 at $90 \%$ power. Physiologic variables, optical density measurements and viable neuronal counts in putamen and caudate nucleus were compared by using one-way ANOVA followed by the Student-Newman-Keuls multiple range test. In the case of viable neuronal counts in neocortex, the equal variance test failed, and the Mann-Whitney rank sum test was used. The neurologic deficit score was analyzed by two-way ANOVA with repeated measures. $\mathrm{p}<0.05$ was considered statistically significant. All values are expressed as means $\pm \mathrm{SD}$, except where noted.

\section{Results}

\section{Mortality and Morbidity}

A total of 65 piglets were studied. Four piglets could not be resuscitated from asphyxial cardiac arrest. Five piglets died or were euthanized within 2 days after resuscitation because of status epilepticus, bronchiole obstruction, nec- rotizing enterocolitis or cardiac failure ( 2 in the vehicle group, 1 in EUK-134 group, and 2 in the edaravone group). Four-day survivors from $\mathrm{HI}$ that were used for neurologic deficit scoring, histology and immunohistochemistry included 8 vehicle-treated piglets ( 4 with saline and 4 with 2 -hydroxypropyl- $\beta$-cyclodextrin), 8 EUK-134-treated piglets and 8 edaravone-treated piglets. Because the HI piglets treated with saline and those treated with 2-hydroxypropyl- $\beta$-cyclodextrin showed no differences in outcomes, these cohorts were combined into a single HIvehicle group for statistical analysis. An additional 8 sham-operated piglets were kept alive for 4 days after treatment with saline $(n=2), 2$-hydroxypropyl- $\beta$-cyclodextrin $(n=2)$, EUK-134 $(n=2)$ or edaravone $(n=2)$. Because there were no differences in the outcomes among the sham-operated animals with the four different treatments, the data were combined into a single sham group. For Western blots in 3-hour survival groups, treatments were limited to saline vehicle and EUK-134 (4 saline-treated sham piglets, 4 EUK-134-treated sham piglets, 8 salinetreated $\mathrm{HI}$ piglets and $8 \mathrm{EUK}-134$-treated $\mathrm{HI}$ piglets).

\section{Physiologic Parameters and Arterial Blood Gas Analysis}

Sham-operated piglets did not show changes in mean arterial blood pressure, heart rate, arterial $\mathrm{pH}$ or arterial partial pressure of $\mathrm{CO}_{2}\left(\mathrm{PaCO}_{2}\right)$ compared with baseline levels (data not shown). All HI groups exhibited similar reductions in $\mathrm{PaO}_{2}$ (table 1) and arterial $\mathrm{O}_{2}$ saturation of hemoglobin (fig. 1) during hypoxia. Moreover, asphyxia produced similar degrees of acidosis, hypercapnia and hyperglycemia (table 1), and similar levels of arterial hypotension and bradycardia (fig. 1) in all HI groups.

\section{Neurologic Deficit Score}

No neurologic deficit was noted in sham piglets. In HI piglets, treatment with EUK-134 or edaravone significantly reduced the overall neurologic deficit scores $(0-$ 154 scale) compared with those of the vehicle-treated group when examined at day 1 after ROSC (fig. 2). Thereafter, the overall deficit score improved in all groups, and differences among the three groups were no longer significant. The primary difference among groups on day 1 was in motor function deficits comprising muscle tone, postural reflexes and mobility/gait assessments. On a composite scale of $0-46$ points, motor function deficits at day 1 were greater in the vehicle group $(16 \pm 8)$ than in the EUK-134 group (9 \pm 2$)$ and edaravone group $(9 \pm 4)$. Motor deficits improved progressively within each group, and differences were not significant on subsequent days. 
Table 1. Arterial blood analysis during hypoxia-asphyxia and recovery

\begin{tabular}{|c|c|c|c|c|c|c|c|}
\hline & Baseline & $\begin{array}{l}\text { Hypoxia } \\
37 \text { min }\end{array}$ & $\begin{array}{l}\text { Room air } \\
5 \mathrm{~min}\end{array}$ & $\begin{array}{l}\text { Asphyxia } \\
5 \text { min }\end{array}$ & \multicolumn{3}{|c|}{ After resuscitation } \\
\hline Vehicle & $7.48 \pm 0.02$ & $7.37 \pm 0.12$ & $7.34 \pm 0.14$ & $6.93 \pm 0.06$ & $7.41 \pm 0.05$ & $7.50 \pm 0.03$ & $7.51 \pm 0.05$ \\
\hline EUK-134 & $7.45 \pm 0.03$ & $7.35 \pm 0.10$ & $7.34 \pm 0.11$ & $6.90 \pm 0.09$ & $7.39 \pm 0.05$ & $7.49 \pm 0.03$ & $7.50 \pm 0.05$ \\
\hline Edaravone & $7.44 \pm 0.05$ & $7.35 \pm 0.06$ & $7.37 \pm 0.08$ & $6.89 \pm 0.06$ & $7.41 \pm 0.08$ & $7.49 \pm 0.05$ & $7.49 \pm 0.03$ \\
\hline EUK-134 & $144 \pm 9$ & $20 \pm 1$ & $77 \pm 14$ & $9 \pm 6$ & $132 \pm 19$ & $146 \pm 7$ & $147 \pm 16$ \\
\hline Edaravone & $130 \pm 18$ & $21 \pm 3$ & $89 \pm 10$ & $9 \pm 3$ & $119 \pm 24$ & $137 \pm 22$ & $144 \pm 24$ \\
\hline \multicolumn{8}{|l|}{$\mathrm{PaCO}_{2}, \mathrm{~mm} \mathrm{Hg}$} \\
\hline Vehicle & $37 \pm 6$ & $36 \pm 6$ & $36 \pm 5$ & $79 \pm 19$ & $36 \pm 4$ & $34 \pm 5$ & $32 \pm 5$ \\
\hline EUK-134 & $37 \pm 4$ & $34 \pm 5$ & $37 \pm 2$ & $93 \pm 10$ & $38 \pm 5$ & $33 \pm 2$ & $33 \pm 4$ \\
\hline Edaravone & $101 \pm 58$ & $185 \pm 74$ & $168 \pm 56$ & $293 \pm 85$ & $183 \pm 52$ & $111 \pm 33$ & $106 \pm 50$ \\
\hline
\end{tabular}

Values are means \pm SD measured at $37 \mathrm{~min}$ of hypoxia, $5 \mathrm{~min}$ of room air ventilation, $5 \mathrm{~min}$ of asphyxia, and $3 \mathrm{~h}$ of recovery in vehicle-, EUK-134- and edaravone-treated groups destined to survive 4 days. No differences were observed among groups.

\section{Histologic Examination}

Administration of 2-hydroxypropyl- $\beta$-cyclodextrin (vehicle for edaravone), EUK-134 or edaravone did not produce any apparent neuronal degeneration in HEstained striata of sham-operated piglets (fig. 3). Neuronal densities in the putamen of sham-operated piglets treated with 2-hydroxypropyl- $\beta$-cyclodextrin, EUK-134 and edaravone were $100 \pm 8,100 \pm 13$ and $99 \pm 6 \%$, respectively, of the values for the saline-treated piglets. In HI piglets treated with either vehicle, most of the principal neurons in the putamen underwent ischemic neurodegeneration (saline treatment: $12 \pm 6 \%$ of sham; 2 hydroxypropyl- $\beta$-cyclodextrin treatment: $11 \pm 7 \%$ of sham). By comparison, the percentage of viable neurons in the putamen at 4 days after ROSC was significantly greater with either EUK-134 or edaravone treatment (fig. 3i). However, the number of viable neurons remained significantly lower than that for the sham group. In agreement with previous work [18], injury to the caudate nucleus was less severe than to the putamen. A significant increase in the number of viable neurons was also detected in HI piglets with EUK-134 or edaravone treatment (fig. $3 \mathrm{j}$ ), although the values remained lower than those for the sham group.

Within the neocortex, the primary sensorimotor cortex is vulnerable to $\mathrm{HI}$ in newborn piglets, and neuronal loss is prominent in layer V [18]. Analysis of viable neurons in layer $\mathrm{V}$ of the parasagittal gyrus indicated a significant loss of neurons in HI piglets treated with vehicle (fig. 4). Treatment with edaravone significantly increased the number of viable neurons, although the density remained lower than that in sham controls. Results with EUK-134 treatment were bimodal: 2 piglets had values $<10 \%$ of sham controls, and 6 piglets had values $>75 \%$ of sham controls. Consequently, nonparametric analysis indicated that cortical neuronal density after EUK-134 treatment was not significantly different from that in either the HI-vehicle group or the sham control group (fig. 4).

\section{Nucleic Acid Immunostaining}

Consistent with previous work [21, 24], faint labeling of the cytoplasm of striatal neurons of sham-operated piglets was detected with the 8-OHdG antibody, corresponding to RNA labeling, whereas the nucleus and the neuropil were free of immunoreactivity (fig. 5a). After $\mathrm{HI}$, cytoplasmic and nuclear immunolabeling became more intense, and the extent of staining in putaminal neurons was significantly greater in the HI than in the sham group (fig. 5b). Treatment with EUK-134 or edaravone after $\mathrm{HI}$ markedly reduced this augmented immunoreactivity. Brain sections from HI piglets processed 
Fig. 1. Arterial $\mathrm{O}_{2}$ saturation, mean arterial pressure and heart rate are plotted for HI piglets treated with vehicle, EUK-134 or edaravone at $30 \mathrm{~min}$ of reoxygenation. Values are means \pm SD measured: at baseline; at 5, 15, 27 and 37 min of hypoxia; at 5 min of room air (RA) ventilation; at each minute of a 7-min period of complete asphyxia (Asph.), and during $3 \mathrm{~h}$ of reoxygenation (note break and change in time scale).

Fig. 2. Neurologic deficit scores $( \pm S D)$ of piglets in the vehicle-treated, EUK-134treated and edaravone-treated groups ( $\mathrm{n}=$ 8 per group) at 1-4 days of recovery from HI. Maximum score $=154 .{ }^{*} \mathrm{p}<0.05$ vs. vehicle.
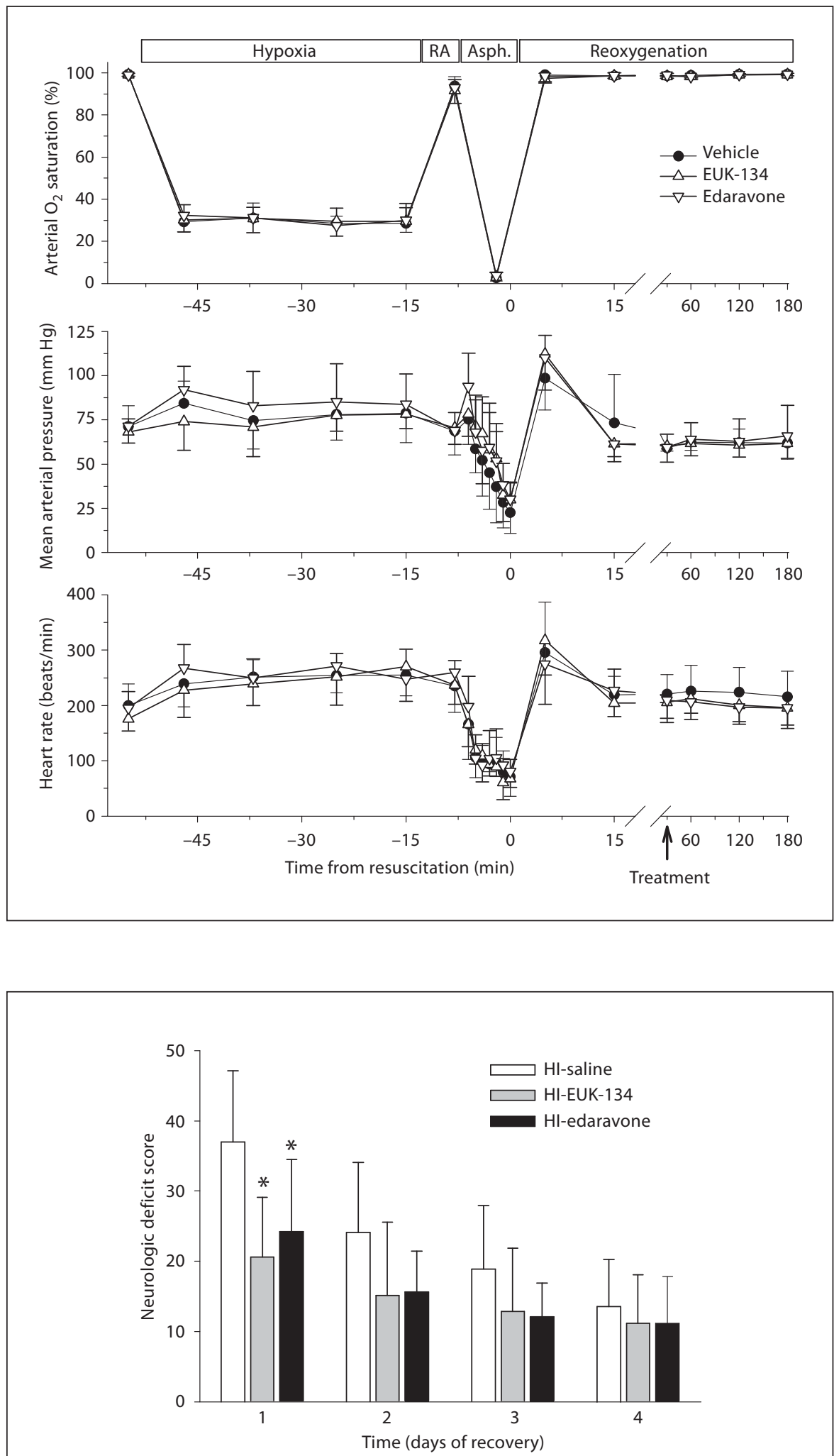


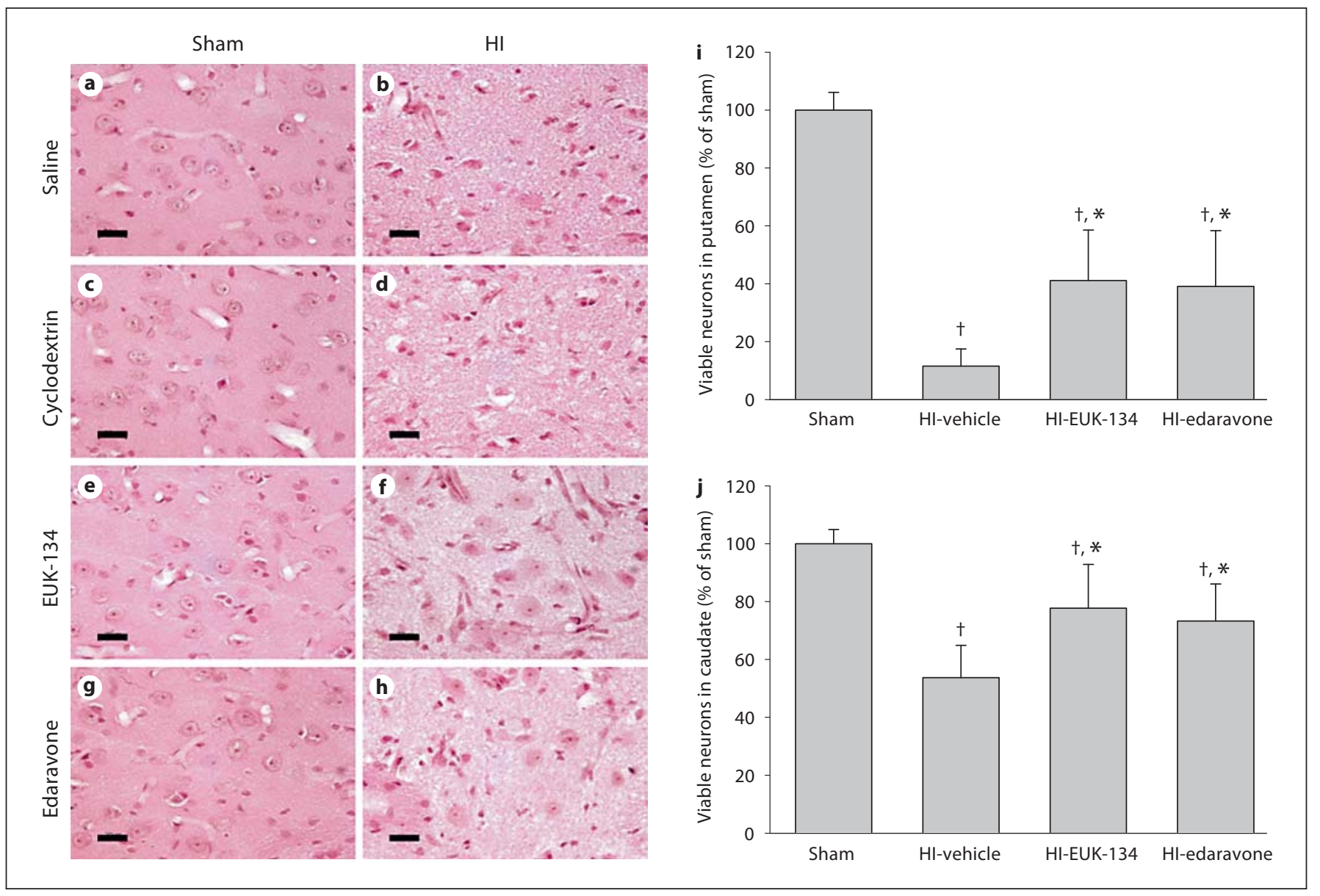

Fig. 3. Neuropathology seen in HE-stained sections of piglet putamen 4 days after sham surgery or HI. In time-matched sham controls administered saline (a), 2-hydroxypropyl- $\beta$-cyclodextrin (c), EUK-134 (e) and edaravone (g), neurons appeared with a normal round shape, noncondensed nucleus and discrete nucleolus. The neuropil is smooth and uniform. In HI piglets treated with saline (b) and 2-hydroxypropyl- $\beta$-cyclodextrin (d), most of the principal striatal neurons underwent ischemic neurodegeneration, and the surrounding neuropil became pale and vacuolated.
In HI piglets treated with EUK-134 (f) or edaravone (h), some of the neurons remained undamaged. Scale bars $=20 \mu \mathrm{m}$. Mean values \pm SD of neuronal viability in putamen (i) and caudate nucleus (j) after sham surgery [combined cohorts with saline $(\mathrm{n}=2), 2$-hydroxypropyl- $\beta$-cyclodextrin $(\mathrm{n}=2), \mathrm{EUK}-134(\mathrm{n}=2)$ and edaravone $(\mathrm{n}=2)$ ] or $\mathrm{HI}$ in piglets treated with vehicle [combined cohorts with saline $(n=4), 2$-hydroxypropyl- $\beta$-cyclodextrin $(n=4)$ ], EUK-134 $(n=8)$ or edaravone $(n=8) .{ }^{\dagger} \mathrm{p}<0.05$ vs. sham surgery; ${ }^{*} \mathrm{p}<0.05$ vs. HI-vehicle. without primary antibodies were used as negative controls for 8-OHdG and 8-nitroguanosine and showed no staining.

8-Nitroguanosine immunolabeling was not obvious in putamen from sham piglets, whereas intense immunopositive staining of the cytoplasm was apparent in putaminal neurons of vehicle-treated HI piglets (fig. 5c). Treatment with EUK-134 or edaravone after HI substantially diminished 8-nitroguanosine immunoreactivity in striatal neurons (fig. 5d).

Neuroprotection from Neonatal HI by Antioxidant Treatment

\section{Protein Oxidation (Protein Carbonyl and 3-Nitrotyrosine)}

Immunoblot analysis revealed an increased abundance of protein carbonyl groups (markers of oxidatively modified proteins) after $\mathrm{HI}$ in the vehicle group (fig. 6a). Treatment with EUK-134 significantly reduced the HIinduced increase in protein carbonyl formation at $3 \mathrm{~h}$ of recovery (fig. 6b).

An intensely reacting band of proteins at $50 \mathrm{kDa}$ showed nitration in control putamen (fig. 6c). The nitrotyrosine modification of this $50-\mathrm{kDa}$ protein, along with 


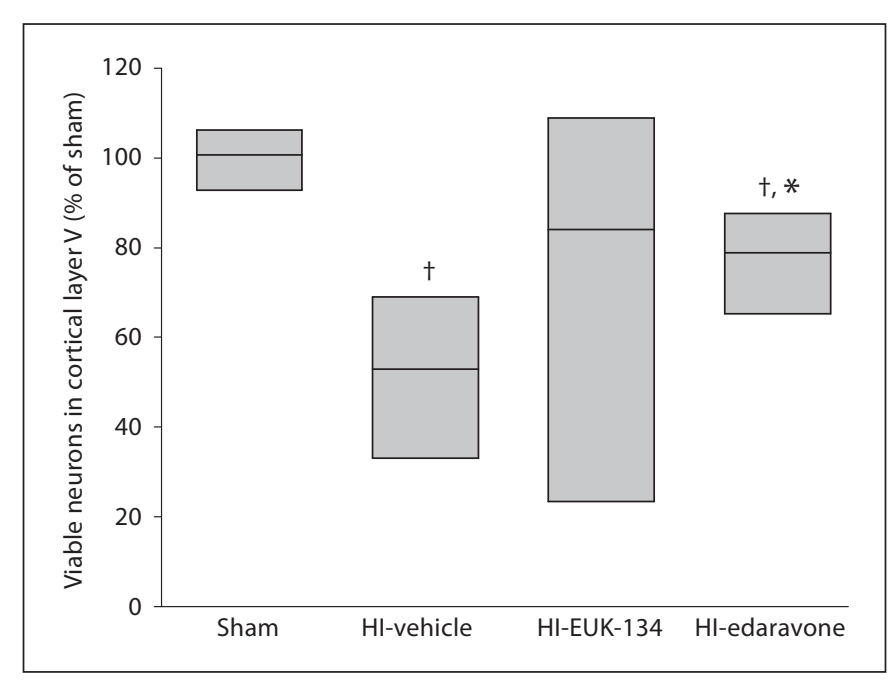

Fig. 4. Density of viable neurons in layer V of primary sensorimotor cortex 4 days after sham surgery or $\mathrm{HI}$ in piglets treated with vehicle, EUK-134 or edaravone ( $n=8$ per group). Neuronal density was bimodal in the EUK-134 group, and the equal variance test failed. Data were analyzed by the Mann-Whitney nonparametric test, and results are displayed as a box plot (median and 25 th and 75 th percentiles). ${ }^{\dagger} \mathrm{p}<0.05$ vs. sham surgery; ${ }^{*} \mathrm{p}<0.05$ vs. HI-vehicle.

other bands, was increased at $3 \mathrm{~h}$ after HI. Treatment with EUK-134 largely reduced nitrotyrosine immunoreactivity for all bands after HI, but had no effect in shamoperated animals (fig. 6d).

\section{Discussion}

We studied neurodegeneration in a newborn animal model of $\mathrm{HI}$ that causes brain damage very similar to the pattern of injury found in human newborns who have experienced HI [18, 37, 38]. The clinical and neuropathological features of the piglet model used in the present study are very different from those of the more commonly used newborn rat models $[18,39]$. In this piglet model of $\mathrm{HI}$, the basal ganglia are selectively vulnerable, and the striatum is the most vulnerable $[18,37]$. The striatal neurons develop oxidative stress, organelle disruption by $3 \mathrm{~h}$ of recovery, and ischemic cytopathology over 6-24 h of recovery [21].

After HI, the newborn brain experiences a cascade of toxic events that begins with energy failure and involves glutamate release, activation of $N$-methyl-D-aspartic acid (NMDA) receptors, calcium influx and excessive production of NO [40]. These dynamic changes result in further mitochondrial dysfunction with superoxide leakage and formation of other ROS such as hydrogen peroxide $[4,5]$. Although it occurs in the course of normal physiologic processes, oxidative stress is a principal contributor to the pathogenesis of HI complications through increased oxidative/nitrosative injury. Oxidants can damage all biologic molecules: DNA, RNA, lipids, proteins, carbohydrates and antioxidants. Increasingly, evidence points to oxidative stress as the major cause of mitochondrial damage and neurodegeneration after acute injuries. These include carbonylation reactions, 4-hydroxynonenal modification and peroxynitrite reaction with tyrosines to generate 3-nitrotyrosine. The formation of peroxynitrite from NO and superoxide has been reported to suppress mitochondrial oxygen consumption and to attenuate postischemic cell function, but these effects can be ameliorated by EUK-134 [41, 42]. Therefore, the neuroprotective effects of antioxidants are clinically relevant to the treatment of neonatal HI [43]. Based on the widespread subcellular damage and the rate of progression of neuronal death in the striatum, the early neurodegeneration in the striatum after $\mathrm{HI}$ in newborns is likely oxidative stress-induced cellular necrosis [44] and, hence, should be treatable with antioxidant drugs.

Agents that interfere with the ROS cascade, such as the xanthine oxidase inhibitor allopurinol and the iron chelator deferoxamine, have been found to be neuroprotective in rodent models of neonatal $\mathrm{HI}[9,10,45]$. Although these agents helped restore cerebral energy metabolism and reduce vasogenic edema in a piglet model of $\mathrm{HI}$, neuroprotection was not robust in piglets [46], and a clinical trial of newborns with severe $\mathrm{HI}$ encephalopathy did not find improved outcome with postnatal allopurinol treatment [47]. By focusing on the striatum, a brain region highly vulnerable in human newborns $[19,20]$ and where oxidative stress is prominent in animal models [21-24], we were able to demonstrate significant neuroprotection by treatment with EUK-134 or edaravone at 30 min of recovery in piglets. Thus, antioxidant treatment is effective in a large-animal model of neonatal HI.

In our study, neuroprotection was incomplete, with less than $50 \%$ of the neurons in the putamen and less than $80 \%$ of the neurons in the caudate nucleus still viable at 4 days of recovery. Optimal efficacy will be influenced by the dosage and timing of drug administration. The drug doses used in the present study were based on the doses shown to be effective in other models. Perhaps the optimal dose differs in piglets. Furthermore, in most studies on postnatal rodents, neuroprotective drugs were usually administered immediately after reoxygenation. We chose 


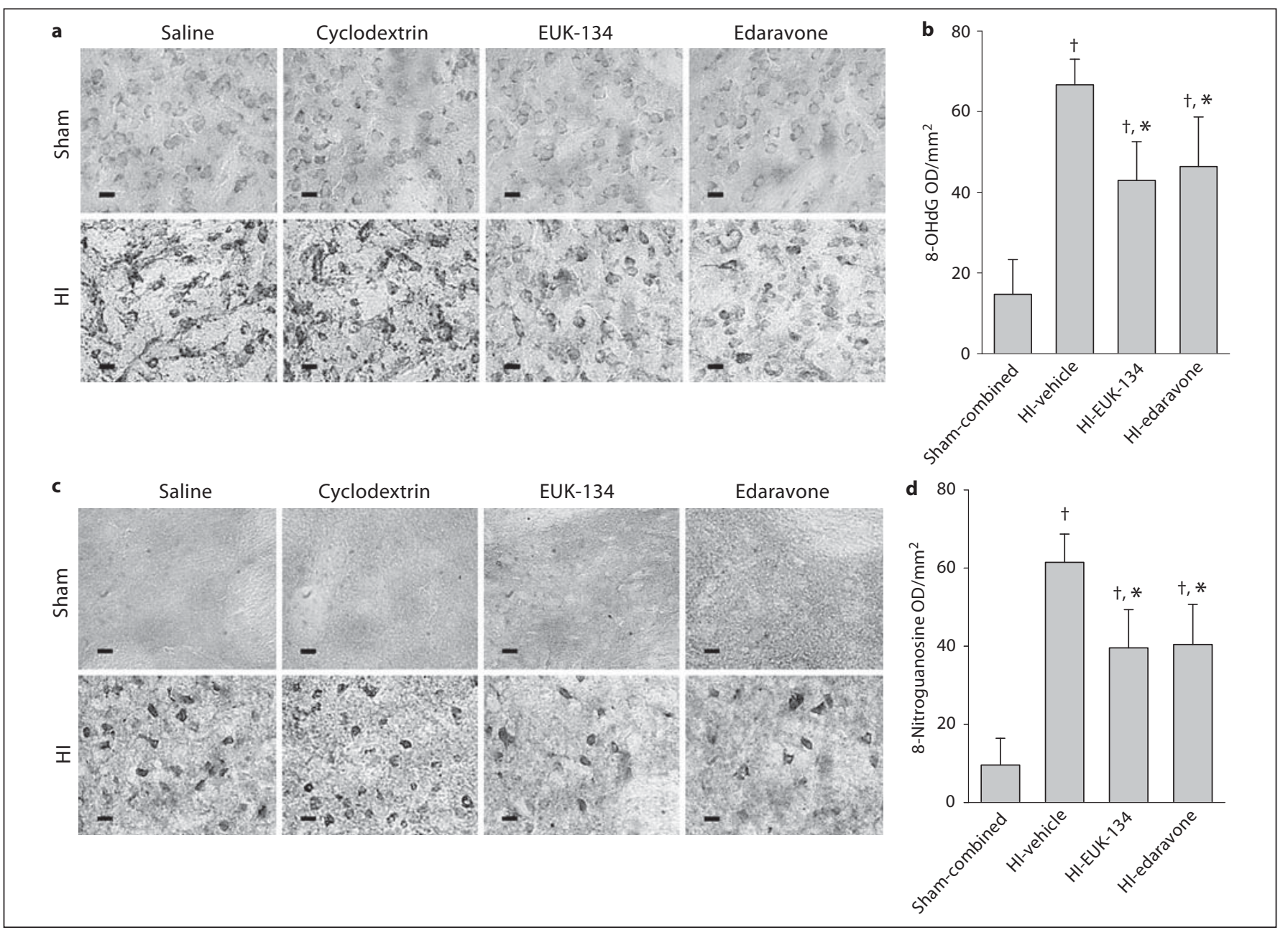

Fig. 5. a In the sham groups, immunohistochemical analysis revealed faint staining for 8-OHdG within the cytoplasm and nucleus. The extent of staining for $8-\mathrm{OHdG}$ was greater in the HI groups treated with saline or 2-hydroxypropyl- $\beta$-cyclodextrin vehicle than in the sham groups. Treatment of HI piglets with EUK-134 or edaravone reduced the staining. b Mean optical density (OD) values for 8-OHdG in the putamen of each group at 4 days of recovery. c Immunohistochemical analysis revealed no discrete positive

to delay the drug infusion by $30 \mathrm{~min}$ after reoxygenation because drugs can rarely be administered to newborns immediately after birth. Although the 30 -min delay is short compared with that typically attained in clinical neonatal HI trials [47], we kept the delay short to demonstrate proof of principle of an oxidative stress-based mechanism of injury in piglets. Additional work would be required to fully evaluate the therapeutic window of these drugs. Because nearly all striatal neurons can be rescued in this model when hypothermia is initiated at 5 min of reoxygenation [36], all neurons have the poten- staining for 8-nitroguanosine within the cytoplasm or nucleus in the sham groups. The extent of staining for 8-nitroguanosine was greater in the vehicle-treated HI groups than in the sham groups. Treatment of piglets with EUK-134 or edaravone reduced immunoreactivity after HI. d Mean OD values for 8-nitroguanosine in the putamen of each group at 4 days of recovery. $\mathbf{a}, \mathbf{c}$ Scale bars $=$ $10 \mu \mathrm{m} . \mathbf{b}, \mathbf{d}$ Values are means $\pm \mathrm{SD}$ ( $\mathrm{n}=8$ per group). ${ }^{\dagger} \mathrm{p}<0.05$ vs. sham-combined; ${ }^{*} \mathrm{p}<0.05$ vs. HI-vehicle. tial to be salvaged by drug therapy. However, delaying hypothermia to $4 \mathrm{~h}$ of recovery in this model provided only partial striatal protection [unpubl. obs.], thereby indicating a limited therapeutic window in this model. Perhaps treatment with EUK-134 or edaravone would be able to rescue additional neurons if administered at the onset of reoxygenation rather than after having delayed treatment by $30 \mathrm{~min}$. Clinically, antioxidant treatment may need to be administered to the mother during difficult labor to optimize neuroprotection, as has been suggested with allopurinol [47]. 
Fig.6. a Representative immunoblot showing DNP immunoreactivity as a measure of protein carbonylation in putamen sampled at $3 \mathrm{~h}$ of recovery from sham or HI piglets treated with saline or EUK-134. b Mean values $\pm \mathrm{SD}(\mathrm{n}=4$ per group) of total carbonyl optical density (OD) expressed as percentage of sham-saline values in putamen at $3 \mathrm{~h}$ of recovery. c Representative immuno-blot of 3-nitrotyrosine immunoreactivity as a measure of protein nitration in putamen sampled at $3 \mathrm{~h}$ of recovery from sham or HI piglets treated with saline or EUK-134. d Mean values \pm $\mathrm{SD}$ ( $\mathrm{n}=4$ per group) of total nitrotyrosine OD expressed as percentage of sham-saline values in putamen at $3 \mathrm{~h}$ of recovery. a, c Synaptophysin (p38) was used as a protein loading control. b, $\mathbf{d}^{\dagger} \mathrm{p}<0.05$ vs. sham-saline, ${ }^{*} \mathrm{p}<0.05$ vs. HI-saline.

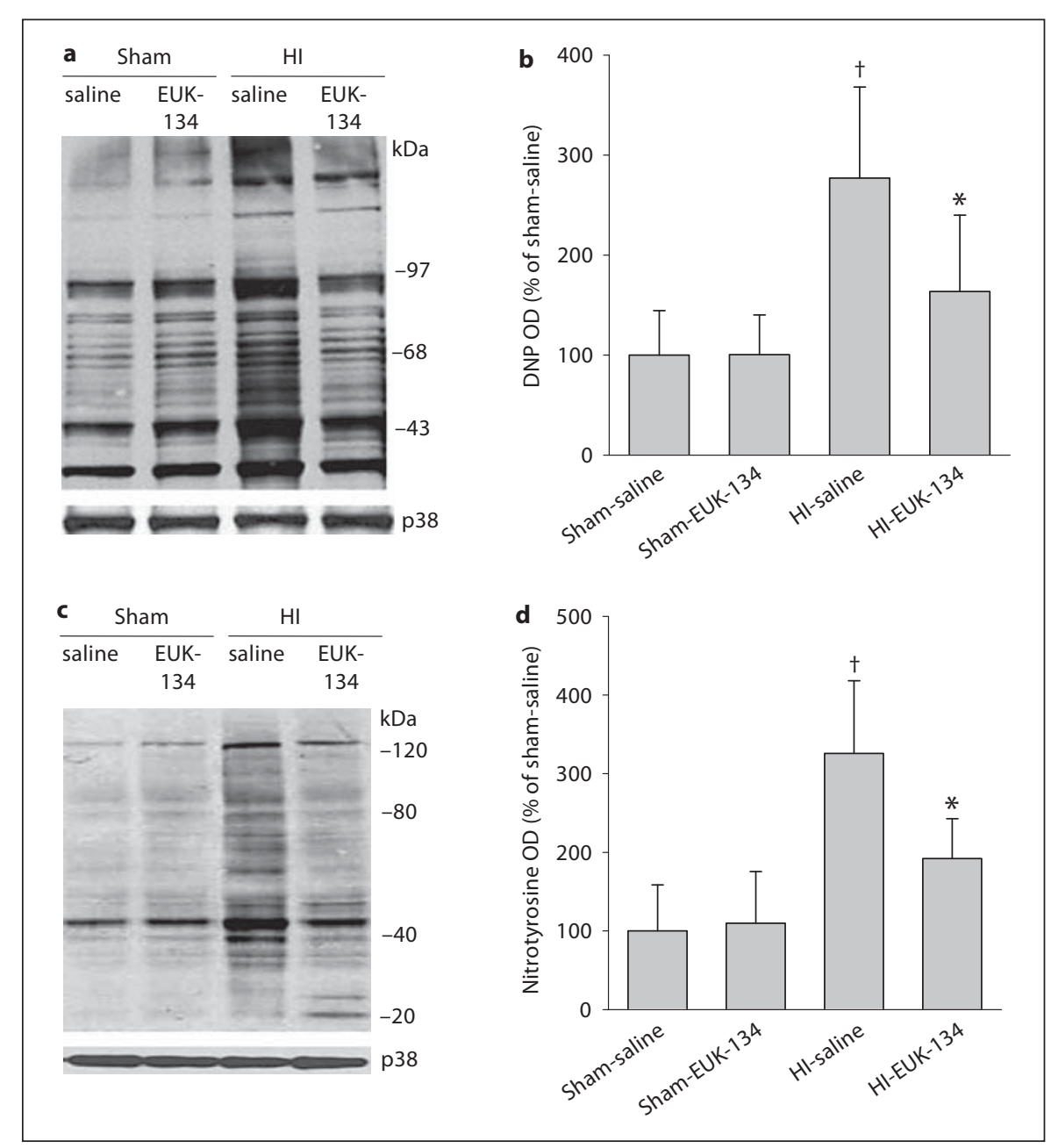

EUK-134 is a diphenol salen compound - having a coordinated Mn ion with the ability to redox cycle between $\mathrm{Mn}$ (III) and Mn(II) states - that can act as a catalytic antioxidant with SOD and catalase-mimetic scavenging properties for superoxide, hydrogen peroxide and peroxynitrite [31]. EUK-134 is a complex of Mn with salen chelating ligand, whereas in $\mathrm{Mn}$ porphyrins, $\mathrm{Mn}$ is ligated to different porphyrin ligands. Yet, all of them share the same redoxable metal center, $\mathrm{Mn}$, where redox-based scavenging of reactive species happens, which in turn leads to suppression of oxidative stress injury [27]. The ability of EUK-134 to cross the blood-brain barrier in a therapeutically relevant concentration has not been shown. New generations of some Mn-centered porphyrin compounds have greater lipophilicity and gastric absorption than some Mn-salen compounds that have a multiple charge [48]. One of the uncharged metalloporphyrins has been reported to cross the blood-brain barrier [49].
EUK-134, with a single charge, may be expected to have intermediate lipophilicity. Sufficient EUK-134 may gain access to the brain not only by virtue of its lipophilicity, but also through a generalized increase in small-molecule permeability that can occur at the piglet blood-brain barrier after resuscitation from cardiac arrest [50].

Catalytic antioxidants have previously been used in other models of cerebral ischemia. In the adult rat, EUK134 administered intravenously $(0.25$ and $2.5 \mathrm{mg} / \mathrm{kg}$, bolus) $3 \mathrm{~h}$ after focal ischemia dramatically reduced infarct volume at $21 \mathrm{~h}$ (by approx. $90 \%$ with a $2.5 \mathrm{mg} / \mathrm{kg}$ dose) [32], but other indices of injury were not assessed. The metalloporphyrin compound MnTE-2-PyP ${ }^{5+}$ [AEOL10113; Mn(III) meso-tetrakis( $N$-ethylpyridinium2-yl)porphyrin] has been used in an adult rat model of transient focal cerebral ischemia and it produces significant infarct volume reduction and neurologic improvement after delivery as a single dose (300 $\mathrm{ng}$ ) into the ce- 
rebral ventricle at $60 \mathrm{~min}$ before ischemia, or at 5 or 90 min or $6 \mathrm{~h}$ after ischemia [51]. This study also showed metalloporphyrin-attenuating aconitase inactivation and 8-OHdG formation. A different metalloporphyrin, MnDE-2-ImP ${ }^{5+}$ [AEOL10150; Mn(III) meso-tetrakis $\left(N, N^{\prime}\right.$-diethylimidazolium-2-yl)porphyrin], also reduced infarct volume, improved neurologic recovery and diminished inflammatory gene expression in an adult rat model of transient focal cerebral ischemia when delivered as a single intraventricular bolus or as a sustained infusion [52]. Interestingly, protection was not sustained at 8 weeks of recovery after a single injection, whereas continuous intraventricular infusion of metalloporphyrin for 1 week provided better protection at 8 weeks of recovery [52]. Thus, targeting secondary oxidative damage and delayed aberrant activation of signaling pathways is important to achieve superior neuroprotection. In our study, we used intravenous infusion of antioxidants rather than intraventricular infusions because systemic administration can be more readily applied to clinical use. However, because of the large amount of drugs required for piglets compared with rodents, the duration of the maintenance infusion was limited to the first $4 \mathrm{~h}$ of recovery for EUK134 and the first $6 \mathrm{~h}$ of recovery for edaravone. These durations were chosen based on the knowledge that striatal neurons are beginning to die by $6 \mathrm{~h}$. Although it is possible that longer infusion durations may maximize neuroprotection in piglets, there is also evidence that prolonged administration of antioxidants may actually be detrimental to the developing brain. For example, administration of edaravone daily for 10 days after $\mathrm{HI}$ in $\mathrm{P} 7$ rats resulted in loss of efficacy compared with that seen with 2 days of administration. Thus, caution is required when extrapolating the benefit of prolonged use of an antioxidant in focal cerebral ischemia in an adult animal to an $\mathrm{HI}$ insult in an immature animal.

In addition to protective effects in the striatum, early treatment with edaravone provided significant but incomplete neuroprotection in the primary sensorimotor cortex. However, results for the cortex with EUK-134 were more variable, with 6 of 8 piglets showing high levels of neuronal viability, but 2 of 8 piglets showing poor viability. In this model, neurodegeneration in the neocortex proceeds more slowly (between 1 and 2 days of recovery) than in the striatum. Here again, a longer duration of antioxidant infusion may be required to show maximal protection in the neocortex.

Both edaravone and EUK-134 treatment improved assessments of motor function and overall neurologic function at 1 day of recovery. However, motor and overall neu-

Neuroprotection from Neonatal HI by Antioxidant Treatment rologic deficits progressively decreased on subsequent days in each group, and differences among groups were no longer significant. This progressive neurologic improvement may reflect a time-dependent restoration of physiologic function and connectivity among remaining viable neurons and/or an establishment of new neuronal circuits to replace connections from dead neurons. More sophisticated behavioral tests need to be developed to detect the loss of striatal function in neonatal piglets.

The striatal protection in EUK-134- and edaravonetreated piglets was supported by robust biochemical data. 8-OHdG, one of the major DNA base-modified products, is an established marker of DNA damage. It is induced by hydroxyl radicals, singlet oxygen or photodynamic action and is known to be mutagenic in its pairing with adenine as well as cytosine, a characteristic that leads to G:C-to-T:A transversion at DNA replication [53]. Here, we showed that both EUK-134 and edaravone were able to markedly reduce the formation of $8-\mathrm{OHdG}$, a finding that supports an antioxidant mechanism of action of these agents. Both agents also reduced immunoreactivity for 8-nitroguanosine after HI.

Previous work demonstrated that a $\sigma$-receptor agonist, which reduced the association of neuronal NO synthase with postsynaptic density 95 and NMDA receptor NR2 subunit after HI, could also reduce 8-nitroguanosine immunoreactivity in piglet striatum [24]. Thus, the HI-induced increase in 8-nitroguanosine immunoreactivity appears to depend on neuronal NO synthase coupling to NMDA receptors. Since edaravone is thought to reduce NO bioavailability, the reduced 8-nitroguanosine immunoreactivity may be explained by scavenging of NO. Because EUK-134 is capable of decreasing the bioavailability of superoxide, $\mathrm{NO}$ and peroxynitrite [31], its ability to reduce 8-nitroguanosine immunoreactivity may be secondary to decreased NO bioavailability and to decreased nucleic acid attack by reactive nitrogen species such as a peroxynitrite.

Protein oxidation causes the loss of protein function, cellular dysfunction and, ultimately, cell death. Oxidative damage can be measured by determining levels of protein carbonyls and tyrosine nitration. Protein carbonyls can arise from direct oxidation of amino acid side chains (His, Pro, Arg, Lys, Thr, etc.), by oxidative cleavage of proteins via the $\alpha$-amidation pathway, or by addition of $\alpha, \beta$-unsaturated aldehydes such as 4-hydroxy-2-nonenal, malondialdehyde and prop-2-enal (acrolein), derived from lipid peroxidation. The levels of protein carbonyls reflect the level of protein oxidation in a cell. Significant oxidative damage to striatal soluble proteins was previ- 
ously found at $3 \mathrm{~h}$ after $\mathrm{HI}$ and prior to identification of neuronal cell death [22]. Proteins at a size of $50 \mathrm{kDa}$ appeared to be prominent targets of oxidative stress, although the identities of these proteins are not yet known. Our results confirm a substantial increase in carbonyl formation at $3 \mathrm{~h}$ after $\mathrm{HI}$ in piglet putamen. Moreover, protein oxidative damage was alleviated by treatment with EUK-134. Therefore, EUK-134 acts to protect both nucleic acids and proteins from oxidative alterations.

Tyrosine nitration is another form of protein oxidation that is associated with HI. Peroxynitrite derived from superoxide and $\mathrm{NO}$ is known to lead to nitration of tyrosine residues. Nitration of proteins results in the inactivation of several important mammalian proteins such as $\mathrm{Mn}$ $\mathrm{SOD}, \mathrm{Cu} / \mathrm{Zn}-\mathrm{SOD}$, actin and tyrosine hydroxylase, and likely interferes with tyrosine phosphorylation-mediated cell signaling as a result of steric effects. Nitrotyrosine immunoreactivity has been detected in the central nervous system of human newborns who died from neurologic complications of birth asphyxia $[54,55]$. In piglet striatum, the increase in 3-nitrotyrosine immunoreactivity precedes neuronal cell death and is associated with abundant cytoskeletal proteins and with a disrupted Golgi ap- paratus [21]. The present results demonstrate that early treatment with EUK-134 suppresses HI-induced protein nitration, presumably by decreasing superoxide and NO bioavailability - which together form peroxynitrite - or by directly oxidizing peroxynitrite [31]. Thus, EUK-134 may act to ameliorate multiple consequences of oxidative and nitrative stress for diverse proteins.

In summary, two structurally different antioxidant drugs intravenously administered to piglets at $30 \mathrm{~min}$ after HI reduced markers of oxidative and nitrative stress on proteins and nucleic acids and resulted in partial neuroprotection in the highly vulnerable striatum, where oxidative stress is evident and neuronal cell death progresses at a rapid rate. These results from a large-animal model of neonatal HI encephalopathy support the early use of antioxidant treatment for neonatal HI encephalopathy.

\section{Acknowledgments}

The authors would like to thank Claire F. Levine, MS, for her editorial assistance. This study was supported by NIH grants NS20020 and NS060703 (R.C.K.) and by an American Heart Association-Phillips Resuscitation Research Fellow Award (Z.-J.Y.).

\section{References}

1 Ferriero DM: Neonatal brain injury. N Engl J Med 2004;351:1985-1995.

2 Gonzalez FF, Ferriero DM: Therapeutics for neonatal brain injury. Pharmacol Ther 2008; 120:43-53.

-3 Ferriero DM: Oxidant mechanisms in neonatal hypoxia-ischemia. Dev Neurosci 2001; 23:198-202.

-4 Lafemina MJ, Sheldon RA, Ferriero DM: Acute hypoxia-ischemia results in hydrogen peroxide accumulation in neonatal but not adult mouse brain. Pediatr Res 2006;59:680 683.

5 Sheldon RA, Christen S, Ferriero DM: Genetic and pharmacologic manipulation of oxidative stress after neonatal hypoxia-ischemia. Int J Dev Neurosci 2008;26:87-92.

6 6 Blomgren $\mathrm{K}$, Hagberg H: Free radicals, mitochondria, and hypoxia-ischemia in the developing brain. Free Radic Biol Med 2006;40: 388-397.

-7 Doverhag C, Keller M, Karlsson A, Hedtjarn M, Nilsson U, Kapeller E, Sarkozy G, Klimaschewski L, Humpel C, Hagberg H, Simbruner G, Gressens P, Savman K: Pharma-cologi$\mathrm{cal}$ and genetic inhibition of NADPH oxidase does not reduce brain damage in different models of perinatal brain injury in newborn mice. Neurobiol Dis 2008;31:133-144.

-8 Palmer C, Vannucci RC, Towfighi J: Reduction of perinatal hypoxic-ischemic brain damage with allopurinol. Pediatr Res 1990; 27:332-336.

-9 Palmer C, Towfighi J, Roberts RL, Heitjan DF: Allopurinol administered after inducing hypoxia-ischemia reduces brain injury in 7-day-old rats. Pediatr Res 1993;33:405-411.

10 Palmer C, Roberts RL, Bero C: Deferoxamine posttreatment reduces ischemic brain injury in neonatal rats. Stroke 1994;25:10391045.

11 Bågenholm R, Andiné P, Hagberg H: Effects of the 21-amino steroid tirilazad mesylate (U-74006F) on brain damage and edema after perinatal hypoxia-ischemia in the rat. $\mathrm{Pe}$ diatr Res 1996;40:399-403.

12 Wang X, Svedin P, Nie C, Lapatto R, Zhu C, Gustavsson M, Sandberg M, Karlsson JO, Romero R, Hagberg H, Mallard C: $\mathrm{N}$-acetylcysteine reduces lipopolysaccharide-sensitized hypoxic-ischemic brain injury. Ann Neurol 2007;61:263-271

13 Ikeda T, Xia YX, Kaneko M, Sameshima H, Ikenoue T: Effect of the free radical scavenger, 3-methyl-1-phenyl-2-pyrazolin-5-one (MCI-186), on hypoxia-ischemia-induced brain injury in neonatal rats. Neurosci Lett 2002;329:33-36.

14 Noor JI, Ikeda T, Ueda Y, Ikenoue T: A free radical scavenger, edaravone, inhibits lipid peroxidation and the production of nitric oxide in hypoxic-ischemic brain damage of neonatal rats. Am J Obstet Gynecol 2005; 193:1703-1708.

15 Noor JI, Ikeda T, Mishima K, Aoo N, Ohta S, Egashira N, Iwasaki K, Fujiwara M, Ikenoue T: Short-term administration of a new free radical scavenger, edaravone, is more effective than its long-term administration for the treatment of neonatal hypoxic-ischemic encephalopathy. Stroke 2005;36:2468-2474.

-16 Noor JI, Ueda Y, Ikeda T, Ikenoue T: Edaravone inhibits lipid peroxidation in neonatal hypoxic-ischemic rats: an in vivo microdialysis study. Neurosci Lett 2007;414:5-9.

-17 Zhu C, Wang X, Huang Z, Qiu L, Xu F, Vahsen N, Nilsson M, Eriksson PS, Hagberg H, Culmsee C, Plesnila N, Kroemer G, Blomgren $\mathrm{K}$ : Apoptosis-inducing factor is a major contributor to neuronal loss induced by neonatal cerebral hypoxia-ischemia. Cell Death Differ 2007; 14:775-784

18 Martin LJ, Brambrink A, Koehler RC, Traystman RJ: Primary sensory and forebrain motor systems in the newborn brain are preferentially damaged by hypoxia-ischemia. J Comp Neurol 1997;377:262-285.

19 Miller SP, Ramaswamy V, Michelson D, Barkovich AJ, Holshouser B, Wycliffe N, Glidden DV, Deming D, Partridge JC, Wu YW, Ashwal S, Ferriero DM: Patterns of brain injury in term neonatal encephalopathy. J Pediatr 2005; $146: 453-460$. 
20 Rutherford MA, Azzopardi D, Whitelaw A, Cowan F, Renowden S, Edwards AD, Thoresen M: Mild hypothermia and the distribution of cerebral lesions in neonates with hypoxic-ischemic encephalopathy. Pediatrics 2005;116:1001-1006.

-21 Martin LJ, Brambrink AM, Price AC, Kaiser A, Agnew DM, Ichord RN, Traystman RJ: Neuronal death in newborn striatum after hypoxia-ischemia is necrosis and evolves with oxidative stress. Neurobiol Dis 2000;7: 169-191.

-22 Mueller-Burke D, Koehler RC, Martin LJ: Rapid NMDA receptor phosphorylation and oxidative stress precede striatal neurodegeneration after hypoxic ischemia in newborn piglets and are attenuated with hypothermia. Int J Dev Neurosci 2008;26:67-76.

-23 Yang ZJ, Torbey M, Li X, Bernardy J, Golden WC, Martin LJ, Koehler RC: Dopamine receptor modulation of hypoxic-ischemic neuronal injury in striatum of newborn piglets. J Cereb Blood Flow Metab 2007;27:13391351.

-24 Yang ZJ, Carter EL, Torbey MT, Martin LJ, Koehler RC: Sigma receptor ligand 4-phenyl1-(4-phenylbutyl)-piperidine modulates neuronal nitric oxide synthase/postsynaptic density-95 coupling mechanisms and protects against neonatal ischemic degeneration of striatal neurons. Exp Neurol 2010;221: 166-174.

-25 Yoshida H, Yanai H, Namiki Y, Fukatsu-Sasaki K, Furutani N, Tada N: Neuroprotective effects of edaravone: a novel free radical scavenger in cerebrovascular injury. CNS Drug Rev 2006;12:9-20.

-26 Edaravone Acute Brain Infarction Study Group: Effect of a novel free radical scavenger, edaravone (MCI-186), on acute brain infarction: randomized, placebo-controlled, double-blind study at multicenters. Cerebrovasc Dis 2003;15:222-229.

-27 Golden TR, Patel M: Catalytic antioxidants and neurodegeneration. Antioxid Redox Signal 2009;11:555-570.

-28 Doctrow SR, Huffman K, Marcus CB, Tocco G, Malfroy E, Adinolfi CA, Kruk H, Baker K, Lazarowych N, Mascarenhas J, Malfroy B: Salen-manganese complexes as catalytic scavengers of hydrogen peroxide and cytoprotective agents: structure-activity relationship studies. J Med Chem 2002;45:45494558.

29 Pong K, Doctrow SR, Baudry M: Prevention of 1-methyl-4-phenylpyridinium- and 6-hydroxydopamine-induced nitration of tyrosine hydroxylase and neurotoxicity by EUK134 , a superoxide dismutase and catalase mimetic, in cultured dopaminergic neurons. Brain Res 2000;881:182-189.

- 30 Pong K, Doctrow SR, Huffman K, Adinolfi CA, Baudry M: Attenuation of staurosporine-induced apoptosis, oxidative stress, and mitochondrial dysfunction by synthetic superoxide dismutase and catalase mimetics, in cultured cortical neurons. Exp Neurol 2001;171:84-97.
31 Sharpe MA, Ollosson R, Stewart VC, Clark JB: Oxidation of nitric oxide by oxomanganese-salen complexes: a new mechanism for cellular protection by superoxide dismutase/ catalase mimetics. Biochem J 2002;366:97107.

32 Baker K, Marcus CB, Huffman K, Kruk H, Malfroy B, Doctrow SR: Synthetic combined superoxide dismutase/catalase mimetics are protective as a delayed treatment in a rat stroke model: a key role for reactive oxygen species in ischemic brain injury. J Pharmacol Exp Ther 1998;284:215-221.

33 Rong Y, Doctrow SR, Tocco G, Baudry M: EUK-134, a synthetic superoxide dismutase and catalase mimetic, prevents oxidative stress and attenuates kainate-induced neuropathology. Proc Natl Acad Sci USA 1999; 96:9897-9902.

- 34 Shichinohe H, Kuroda S, Yasuda H, Ishikawa T, Iwai M, Horiuchi M, Iwasaki Y: Neuroprotective effects of the free radical scavenger edaravone (MCI-186) in mice permanent focal brain ischemia. Brain Res 2004;1029: 200-206.

35 Zhang W, Sato K, Hayashi T, Omori N, Nagano I, Kato S, Horiuchi S, Abe K: Extension of ischemic therapeutic time window by a free radical scavenger, edaravone, reperfused with tPA in rat brain. Neurol Res 2004; 26:342-348.

- 36 Agnew DM, Koehler RC, Guerguerian AM, Shaffner DH, Traystman RJ, Martin LJ, Ichord RN: Hypothermia for 24 hours after asphyxic cardiac arrest in piglets provides striatal neuroprotection that is sustained 10 days after rewarming. Pediatr Res 2003;54: 253-262.

37 Martin LJ, Brambrink AM, Lehmann C, Portera-Cailliau C, Koehler RC, Rothstein J, Traystman RJ: Hypoxia-ischemia causes abnormalities in glutamate transporters and death of astroglia and neurons in newborn striatum. Ann Neurol 1997;42:335-348.

38 Johnston MV: Selective vulnerability in the neonatal brain. Ann Neurol 1998;44:155156.

39 Brambrink AM, Martin LJ, Hanley DF, Becker KJ, Koehler RC, Traystman RJ: Effects of the AMPA receptor antagonist NBQX on outcome of newborn pigs after asphyxic cardiac arrest. J Cereb Blood Flow Metab 1999;19:927-938.

-40 Buonocore G, Groenendaal F: Anti-oxidant strategies. Semin Fetal Neonatal Med 2007; 12:287-295.

41 Comellas AP, Dada LA, Lecuona E, Pesce LM, Chandel NS, Quesada N, Budinger GR, Strous GJ, Ciechanover A, Sznajder JI: Hypoxia-mediated degradation of $\mathrm{Na}, \mathrm{K}$ ATPase via mitochondrial reactive oxygen species and the ubiquitin-conjugating system. Circ Res 2006;98:1314-1322.

-42 Samai M, Sharpe MA, Gard PR, Chatterjee PK: Comparison of the effects of the superoxide dismutase mimetics EUK-134 and tempol on paraquat-induced nephrotoxicity. Free Radic Biol Med 2007;43:528-534.
43 McLean C, Ferriero D: Mechanisms of hypoxic-ischemic injury in the term infant. Semin Perinatol 2004;28:425-432.

44 Martin LJ, Al-Abdulla NA, Brambrink AM, Kirsch JR, Sieber FE, Portera-Cailliau C: Neurodegeneration in excitotoxicity, global cerebral ischemia, and target deprivation: a perspective on the contributions of apoptosis and necrosis. Brain Res Bull 1998;46:281309.

-45 Sarco DP, Becker J, Palmer C, Sheldon RA, Ferriero DM: The neuroprotective effect of deferoxamine in the hypoxic-ischemic immature mouse brain. Neurosci Lett 2000; 282:113-116.

46 Peeters-Scholte C, Braun K, Koster J, Kops N, Blomgren K, Buonocore G, Buul-Offers S, Hagberg H, Nicolay K, van Bel F, Groenendaal F: Effects of allopurinol and deferoxamine on reperfusion injury of the brain in newborn piglets after neonatal hypoxia-ischemia. Pediatr Res 2003;54:516-522.

47 Benders MJ, Bos AF, Rademaker CM, Rijken $\mathrm{M}$, Torrance HL, Groenendaal F, van Bel F: Early postnatal allopurinol does not improve short term outcome after severe birth asphyxia. Arch Dis Child Fetal Neonatal Ed 2006;91:F163-F165.

48 Rosenthal RA, Huffman KD, Fisette LW, Damphousse CA, Callaway WB, Malfroy B, Doctrow SR: Orally available Mn porphyrins with superoxide dismutase and catalase activities. J Biol Inorg Chem 2009;14:979-991.

-49 Liang LP, Huang J, Fulton R, Day BJ, Patel M: An orally active catalytic metalloporphyrin protects against 1-methyl-4-phenyl-1,2,3,6tetrahydropyridine neurotoxicity in vivo. J Neurosci 2007;27:4326-4333.

50 Schleien CL, Koehler RC, Shaffner DH, Eberle B, Traystman RJ: Blood-brain barrier disruption after cardiopulmonary resuscitation in immature swine. Stroke 1991;22:477483.

51 Mackensen GB, Patel M, Sheng H, Calvi CL, Batinic-Haberle I, Day BJ, Liang LP, Fridovich I, Crapo JD, Pearlstein RD, Warner DS: Neuroprotection from delayed postischemic administration of a metalloporphyrin catalytic antioxidant. J Neurosci 2001;21:45824592.

52 Sheng H, Yang W, Fukuda S, Tse HM, Paschen W, Johnson K, Batinic-Haberle I, Crapo JD, Pearlstein RD, Piganelli J, Warner DS: Long-term neuroprotection from a potent redox-modulating metalloporphyrin in the rat. Free Radic Biol Med 2009;47:917923.

53 Toyokuni S: Reactive oxygen species-induced molecular damage and its application in pathology. Pathol Int 1999;49:91-102.

54 Groenendaal F, Lammers H, Smit D, Nikkels PG: Nitrotyrosine in brain tissue of neonates after perinatal asphyxia. Arch Dis Child Fetal Neonatal Ed 2006;91:F429-F433.

55 Groenendaal F, Vles J, Lammers H, de Vente J, Smit D, Nikkels PG: Nitrotyrosine in human neonatal spinal cord after perinatal asphyxia. Neonatology 2008;93:1-6. 